\title{
Multiplicidades do movimento: um experimento etnográfico sobre duas caminhadas quilombolas
}

- Pedro Henrique Mourthé

Universidade Federal de Sáo Carlos, São Carlos, Sáo Paulo, Brasil

Yara de Cássia Alves

Universidade de São Paulo, Sáo Paulo, Sáo Paulo, Brasil

DOI 10.11606/issn.2316-9133.v24i24p183-201

resumo $\mathrm{O}$ objetivo central do artigo é analisar o movimento, nas diversas dimensóes que a categoria pode tomar, em dois contextos quilombolas: a comunidade Brejo dos Crioulos e a comunidade Pinheiro, situadas no norte e nordeste de Minas Gerais. Como ponto de conexão entre duas pesquisas e duas realidades sociais, o movimento se relaciona com tipos variados de conhecimento, dentre eles, o conhecimento político. Tentaremos explorar, como esses cotidianos são permeados por circulaçóes de pessoas, animais, informaçôes, notícias, ideias, papéis, ou seja, humanos e não humanos, e como essas circulaçóes promovem um universo muito mais móvel que a burocracia estatal ou jurídica. Enveredando nas teias diárias de idas e vindas, pretendemos iluminar as lutas destes quilombolas, suas caminhadas e andanças, que se fazem em meio ao esforço de promoção das causas de suas comunidades.

palavras-chave Movimento; Etnografia; Socialidade; Conhecimento; Quilombolas.

Multiplicities of the movement: an ethnographic experiment on two quilombola walks

abstract The central objective of this article is to analyze the movement in the various dimensions that the category can take in two quilombola contexts: the Brejo dos Crioulos community and the Pinheiro community, located in the North and Northeast of Minas Gerais. As a connecting point between two researches and two investigations, the movement relates to different kinds of knowledge, among them, political knowledge. We will try to explore how these daily realities are permeated by circulations of people, animals, information, news, ideas, papers, meaning, human and nonhuman circulation, and how these circulations promote a much more mobile universe than state or legal bureaucracy. Develo- 
ping on daily webs of comings and goings we intend to illuminate the struggles of these quilombolas, their walks and wanderings, which are in the midst of efforts to promote the causes of their communities.

keywords Movement; Ethnography; Sociality; Knowledge; Quilombolas.

\section{Introdução}

Este artigo surge como desdobramento de um encontro de dados etnográficos, que se fizeram ressonantes ao serem apresentados no III Seminário de Antropologia da UFSCar. ${ }^{1}$ Ao expormos artigos isolados, observamos que as teorias de nossos interlocutores se cruzavam e revelavam aspectos importantes sobre modos de agir nos sertóes mineiros e na $l u t a^{2}$ quilombola. Foi nesse encontro etnográfico que percebemos que $o$ movimento pode ser desdobrado em múltiplos significados e usos diários, promovendo cotidianos marcados por circulaçóes. São caminhadas e andanças distintas seja dentro das comunidades, entre localidades, para as zonas urbanas, para outras cidades e estados, para atividades de trabalho e atividades políticas - que sáo movidas e refletidas por estes quilombolas sertanejos, revelando universos em que a luta mobiliza elementos cotidianos, ressignificados politicamente.

Assim, pretendemos aqui, explorar as possibilidades de uma "teoria etnográfica”, como proposto por Goldman (2006). Essa teoria vem da tentativa de compreender um aspecto social, produzido em contextos específicos, mas que possa "funcionar como matriz de inteligibilidade em e para outros contextos" (GOLDMAN, 2006, p. 28). Determo-nos aqui nas múltiplas dimensóes do movimento, em duas realidades sociais distintas, e o faremos com o olhar direcionado para as práticas e funcionamentos, evitando abstraçóes e modelos ideais. Esse cuidado vem da proposição de Goldman (2006), para quem a "teoria etnográfica" deve evitar abstraçôes estruturais, funcionais ou processuais. Nos casos aqui abordados, a forma como o cotidiano se permeia de mobilidade não exclui ou isola as maneiras como essas comunidades se pensam politicamente, dentro do movimento quilombola. Percebemos que os movimentos sociais dos quais esses quilombolas fazem parte requerem intensos deslocamentos e relaçóes, uma gama de movimentos que se espraiam no cotidiano de suas localidades.

Assim, para além de esferas jurídicas ou governamentais, nossos olhares estão voltados para os sentidos que as discussóes políticas ganham e produzem nas vidas dos quilombolas, que se alimentam de repertórios externos e mais alargados sem, no entanto, partirem de conteúdos estranhos às suas rotinas e às suas concepçóes sobre a própria existência. Esse enfoque, 
segundo Goldman (2007), foi negligenciado por parte da antropologia, sendo "curioso observar que a literatura sobre movimentos sociais e culturais costuma se dedicar mais às noçóes de sociedade ou cultura do que do aspecto de movimento dos movimentos" (GOLDMAN, 2007, p. 15, grifos nossos). Acreditamos que as lutas políticas que acompanhamos necessitam de uma mobilização intensa de seus participantes. Os moradores precisam circular, conhecer novos locais e vivenciar novas experiências. É preciso lidar com os papéis e fazer encaminhamentos, confeccionar as cartas políticas e garantir que elas circulem.

É necessário mobilizar as redes e isso se dá através de um processo inventivo (WAGNER, 2010), resultante do encontro de criatividades e perspectivas, em que nossos interlocutores vão mobilizando seus saberes, parceiros, estratégias e outros elementos da cosmologia quilombola, dando seguimento às suas lutas. Algo próximo do que aponta a etnografia de Vieira (2015), que propóe um deslocamento analítico, do Estado como ponto de partida para uma "teoria política quilombola", descrevendo como seus próprios interlocutores experienciam a política. Esse movimento permitiu reflexôes sobre como os quilombolas baianos da Malhada vão experimentando termos e palavras na sua ação política junto aos movimentos sociais e no âmbito da política partidária, sobretudo no "tempo da política". Aqui, esse deslizamento contribui para refletirmos sobre como os nossos próprios interlocutores pensam o movimento e a luta.

Assim, partimos da concretude de nossos trabalhos de campo para alargar um pouco o escopo de visualização, assumindo que a etnografia direciona aproximaçóes e permite que discutamos questóes relativas a formas de análise e envolvimento com o mundo que partem de nossos interlocutores. Mais do que um texto com um formato de artigo, fazemos aqui um experimento, uma escrita que mescla a imersáo em campo com uma segunda imersão, longe do campo, o que Strathern (2014) chama de "momento etnográfico". A autora discute a posição do antropólogo enquanto aquele que recria, por meio da escrita, o efeito de práticas e artefatos no cotidiano das pessoas, e por conta disso, deve compreender a complexidade da vida social, sem reduzi-la a princípios ou axiomas. Partindo desse ponto de vista, tentaremos trazer o dinamismo intrínseco ao trabalho etnográfico para a escrita, dinamismo que é adensado por um texto elaborado "a quatro mãos" e gestado por um mosaico de experiências.

Dessa maneira, o texto se organiza em três partes principais, duas apresentações dos contextos etnográficos em questão, os usos e sentidos rotineiros do movimento em cada um deles e, por fim, um esforço de síntese e conexão, não apenas entre as duas etnografias, mas entre outros trabalhos que propuseram reflexóes sobre essa temática. Através das ressonâncias, desenharemos relaçóes a partir deste experimento. 


\section{Um mundo onde tudo gira, gera e mexe: movimentos dos moradores de Pinheiro}

Pinheiro situa-se na zona rural do município de Minas Novas, Alto do Vale do Jequitinhonha - Minas Gerais. Grande parte dos seus moradores se desloca para atividades de trabalho em outras regióes do país, em diferentes tipos de saidas, que se relacionam com o gênero e as faixas etárias. Historicamente, os homens da regiáo saem mais que as mulheres, as quais tendem a sair para Belo Horizonte ou Ribeirão Preto, quando solteiras, para atividades de cuidado doméstico; ou para o café, no Sul de Minas, quando casadas e geralmente sem filhos. Nos últimos cinco anos, as mulheres casadas que decidem sair têm se deslocado para Barrinha, interior de Sáo Paulo, trabalhando diariamente em Ribeirão Preto, em atividades de cuidado doméstico.

Esse deslocamento se relaciona com o fato de que os homens tem se empregado em usinas de isolamento térmico, que os contratam em Barrinha e os direcionam para empreitadas de aproximadamente três meses, em vários estados do Brasil. Portanto, Barrinha é um ponto de parada desses homens, o que motivou a ida de suas mulheres e crianças. Há também homens que trabalham no ramo de construção civil, em Ribeirão Preto e residem em Barrinha, dada a proximidade e o custo de vida mais acessível. Ainda há homens que trabalham no interior paulista, no corte de cana, que por décadas mobilizou a maioria dos moradores. Contudo, o corte de cana é uma tendência decrescente, devido à legislaçáo ambiental que incentiva o corte mecanizado e o fim das queimadas nos canaviais.

Essas saidas para trabalhar se iniciaram na localidade em meados da década de 1960 e são marcadas pela dinamicidade, pois se cruzam com as lógicas do mercado financeiro, com as escolhas familiares de saida em conjunto, com legislaçóes que criam ou reduzem cargos e atividades específicas, dentre outros fatores que foram mais detalhados por Alves (2016). Diante dessas saidas, mas principalmente a partir de movimentos internos à comunidade, como idas à casa de vizinhos, circulação entre terrenos, idas à cidade, circulação de animais, circulação de notícias e telefonemas, os moradores estão sempre observando e refletindo sobre o movimento.

Para eles, o mundo está sempre girando, gerando e mexendo e, por isso, a vida nunca está do mesmo jeito. Mais do que um recurso retórico, essa imprevisibilidade é levada a sério e nada impede que alguém que esteja em Pinheiro se desloque para qualquer outra cidade que tenha um parente, ou que alguém que esteja em outro estado, ou em outra regiáo do país, resolva ir de muda para Pinheiro, o que pode ser resolvido de uma noite para o dia. Observo também que o ir de muda não significa voltar definitivamente, e 
o movimento contrário, a saida, mesmo que acompanhada das mulheres e crianças, não é um rompimento com Pinheiro e nem um estabelecimento completo no outro lugar. São vidas que são vividas sempre com a possibilidade da incerteza, de movimentos múltiplos - encarados de maneiras diversas e altamente valorizados - um motor existencial, muito mais do que um recurso econômico. Para essas pessoas, o corpo parado é o pior que tem e se movimentar é, antes de tudo, condição para uma boa existência.

Assim, repetidas vezes ouvi falar que andar é bom, andando a gente ganha sabedoria. Essa é uma frase amplamente proferida, por homens e mulheres de idades diferentes, o que estabelece uma relação multifacetada entre sabedoria e andanças. Não apenas as andanças nas saidas para trabalhar fazem ganhar sabedoria. Andanças variadas, como na comunidade, também são importantes para que se tenha sabedoria sobre o lugar. É andando que aprendem onde os antepassados moravam, pelos restos de casa que ainda existem nos terrenos, até onde vão as terras de cada família, onde são os pontos de referência.

É preciso conhecer os pontos de referência em Pinheiro, que são provas cabais de que se tem sabedoria do lugar. Portanto, saber onde fica a bananeira de Antônia (bananeira que fica de frente para os restos de casa de D. Antônia, que faleceu há décadas) é fundamental para mostrar sabedoria sobre Pinheiro, tal como acontece quando se retorna: é preciso demonstrar que ainda se sabe andar nas trilhas, carreiros e carretilhas, mesmo que se tenha passado mais de quinze anos fora, como acontece em alguns casos. Aprender a andar faz parte da pedagogia ali vigente, aprende-se desde criança e prescinde-se de demonstraçóes cotidianas, seja ensinando ou ao se contar causos, ao escolher caminhos diferentes de acordo com os objetivos de cada andança.

Andar é importante também na cidade, a zona urbana do município de Minas Novas, estima-se saber andar na cidade para ganhar sabedoria sobre os comércios, as casas de amigos e parentes, os locais onde os habitantes de Pinheiro circulam e onde é possível encontrar carona e um conhecido, dentre outros. Faz parte dos aprendizados da infância saber localizar pontos básicos de referência na zona urbana de Minas Novas, como a sapucaia (árvore que identifica a cadeia local) ou a castanheira, árvore que fica na praça onde os moradores de Pinheiro e região param para fazer um lanche, esperar uma carona ou algum parente que os transportem de volta ou simplesmente para ver o tempo passar. Esses são critérios primordiais para demonstrar que se tem sabedoria da área urbana de Minas Novas, que já se andou por ali, critérios utilizados, por exemplo, para observar se as crianças já são crescidinhas, se estão atentas a essas questóes e se já podem circular mais livremente quando estão na cidade. 
No âmbito político mais amplo, a associação local também se constitui como um vetor de movimentação. Macuco, Pinheiro, Mata Dois e Gravatá são quatro localidades que formam uma associação local, a Associação dos Moradores e Produtores Rurais das Comunidades de Macuco, Mata Dois, Pinheiro e Gravatá (Aprompig), desde 1996. A Aprompig surge da iniciativa dos moradores de se entenderem enquanto coletividade, estimulados pelas Comunidades Eclesiais de Base (CEBs), que marcaram presença na região. Segundo as lideranças da Aprompig, eles fundaram a associação porque observaram que era necessário fazer reunião, que só assim podiam melhorar um pouco a vida na roça, em um momento político que os programas sociais do governo federal eram bem menos efetivos.

Quando tomaram conhecimento do movimento quilombola, essas lideranças da Aprompig promoveram uma série de discussóes sobre o tema, com o auxílio da ONG Centro de Documentação Eloy Ferreira da Silva (CEDEFES) e levaram aproximadamente dois anos (de 2003 a 2005) para acrescentar ao nome da associação o termo "quilombola", embora sem alterar a sigla anterior. Essa mudança ocorreu em uma assembleia extraordinária e foi registrada em cartório, possibilitando assim a requisição do reconhecimento via FCP (Fundaçáo Cultural Palmares). Segundo aquelas lideranças, a inserção no movimento quilombola era vista como uma possibilidade de acesso a políticas públicas específicas, principalmente as ligadas à geração de renda e educação.

As diversas viagens para eventos variados, como encontros quilombolas, lançamentos de projetos, palestras, cursos, geram muitos comentários e aumentam o escopo de lugares visitados e conhecidos. Tal como analisado por Mello (2008), que percebeu o quanto seus interlocutores de Cambará valorizavam a possibilidade de conhecer agentes externos, através do movimento quilombola, em Pinheiro eles admiram a possibilidade de conhecer outros lugares, não apenas fisicamente, mas outras realidades, que são sempre trazidas nos eventos de comunidades tradicionais, em que o histórico e os problemas desses outros lugares são expostos e problematizados.

Saber sobre a vida dos companheiros, que envolve não apenas quilombolas, mas também indígenas, assentados do MST (Movimento dos Trabalhadores Rurais Sem Terra), caiçaras, raizeiros, geraizeiros, dentre outros, alarga o escopo de comparação, e visitar outras cidades e até outros países (como a visita que fizeram à Itália), valoriza ainda mais a necessidade de andar para conhecer, para ganhar sabedoria.

Aos poucos eles vão sendo reconhecidos por esse movimento e a Aprompig se consolida, através do movimento quilombola, que é um caminho para sua maior visibilidade. Digo isso porque somente depois de inserida no movimento quilombola a Aprompig conseguiu uma sede, teve 
aprovados projetos significativos e conquistou mais membros. Assim, não como manejo instrumentalizado, mas como consequência do movimento, a associação local começou a ser vista, a contabilizar no cálculo e no jogo político, seja no âmbito das quatro comunidades ou no âmbito municipal.

Atualmente, a Aprompig conta com aproximadamente duzentos membros, sendo uma das maiores associaçóes do município de Minas Novas. Porém, mais que o número de membros, o que mais motiva as lideranças sáo suas andanças, o movimento que a Aprompig cria em suas vidas, a possibilidade de conhecer outros lugares e ter sabedoria sobre eles. Eles dizem que se antes engatinhavam, nos doze anos anteriores à existência da sede, agora ganharam mais firmeza e conseguem correr atrás. O uso dessas expressóes ligadas ao movimento e ao próprio corpo humano servem de mote para um processo político.

A Aprompig se faz nas andanças de suas lideranças e de seus membros, que se comprometem a acompanhar a associação, que literalmente se faz a partir de corpos que se deslocam. Correr atrás, buscar recursos, buscar projetos são as expressões mais utilizadas para qualificar $o$ movimento quilombola e todas as dinâmicas que ele traz para a vida dessas pessoas. São inúmeros parceiros, e por motivos variados é preciso ir até eles, ligar, passar na instituição em que trabalham. Quanto mais se movimenta, mais projeção se ganha e maiores as possibilidades de ser lembrado e participar de algum projeto, curso ou intervenção. Além disso, quanto mais se anda, mais sabedoria se tem, seja de outras realidades e lugares, como citado, ou sobre burocracias e sobre politica. Em entrevista, o sr. Geraldo afirma que quem vai sempre leva alguma coisa, mas muitas vezes traz muito mais do que aquilo que levou. Porque a gente é vivendo e aprendendo.

Todas essas andanças com a associação se configuram como elemento mais central da Aprompig. É importante ressaltar que, até o momento, os moradores de Pinheiro não reivindicaram a titulação de suas terras junto ao INCRA (Instituto Nacional de Colonização e Reforma Agrária). Eles afirmam não desejarem a mudança na gestão territorial, que historicamente vigora ali a partir de um domínio familiar, chamado de terra no bolo - sistema no qual as famílias determinam o uso e apropriação de seus territórios, sem a necessidade de acordos e delimitaçôes jurídico-formais. ${ }^{3}$

Os moradores afirmam que se organizam a partir desse sistema por avaliarem positivamente a autonomia de gestão de suas terras, costumeiramente divididas e acordadas entre os familiares. Há uma definição das fronteiras de cada terreno, que é informalmente conhecida, mas também eventualmente delimitada por topógrafos, com a finalidade de retirada e pagamento de uma declaraçáo de terras do trabalhador rural, fornecida pelo Sindicato dos Trabalhadores Rurais de Minas Novas. Portanto, a ti- 
tulação territorial não é uma pauta levantada atualmente, o que dá mais visibilidade a busca por projetos, parcerias, viagens e andanças da associação.

Os moradores de Pinheiro se orgulham do fato de não possuírem conflitos territoriais, na atualidade, e conseguirem gerenciar seus terrenos de maneira mais flexível que determinaçôes estatais. Sabem que outras realidades são mais cruéis que a ali vivenciada, devido a pressóes fundiárias e desacordos entre a lei e a ocupação territorial. Para eles, e principalmente para as lideranças, é preciso saber que outros companheiros estão numa luta maior, e o exemplo clássico é Brejo dos Crioulos. "Graças a Deus, náo temos o problema de nossos companheiros, de Brejo. Temos rezado por eles." Esta solidariedade e essa alteridade só foram possíveis graças aos encontros com os companheiros de Brejo, em eventos do movimento quilombola. Saber de outras realidades e andar por outros lugares, em viagens pela associação, é fundamental para reconhecerem as multiplicidades das formas de participaçáo no movimento quilombola. Para compreender melhor por que os moradores de Pinheiro se tranquilizam em não terem a mesma situação territorial de Brejo dos Crioulos e por que rezam por eles, sigamos com a apresentação do contexto desses companheiros.

\section{Movimentos entrelaçados: Brejo dos Crioulos e a luta pelo território}

Brejo dos Crioulos localiza-se no sertáo do Norte de Minas Gerais, na divisa de três municípios - São João da Ponte, Verdelândia e Varzelândia. ${ }^{4}$ Vítimas de um violento processo de expropriação territorial desde meados de 1930, os moradores viviam encurralados pelas fazendas, com acesso restrito ao território. A partir de 1998 os quilombolas começam a realizar suas mobilizaçóes na luta pela retomada do território, dando início aos enfrentamentos dentro e fora da comunidade, com vistas ao processo de titulação. $\mathrm{O}$ cenário de disputas é tecido pelo entrelaçamento de diversas forças políticas.

Frente à morosidade do Estado na desapropriação das fazendas, os quilombolas de Brejo dos Crioulos têm recorrido a duas estratégias nos seus enfrentamentos: as retomadas e a mobilização de uma rede de parceiros e documentos - processos jurídicos, relatórios, laudo antropológico, decretos, correspondências, notas, projetos, boletins de ocorrência etc. - em diferentes instituições e nas várias instâncias judiciais, caracterizando um universo burocrático que é acionado a todo instante.

A luta pela titulação do território já dura dezoito anos, marcados pelas inúmeras caminhadas e mobilizaçóes. As lideranças quilombolas estáo sempre em movimento, suas rotinas são marcadas pelas diversas viagens e 
reuniôes. Os deslocamentos para Montes Claros, Belo Horizonte e Brasília são frequentes, assim como os intercâmbios e as trocas de experiências articulados conjuntamente com os parceiros, nos quais as lideranças vão visitar outras comunidades quilombolas, indígenas, vazanteiros, geraizeiros, outros povos e comunidades tradicionais, assentamentos e acampamentos do MST. Novos lugares, instituiçóes e espaços políticos vão sendo descobertos e passam a fazer parte do cotidiano dessas pessoas. ${ }^{5}$

Os deslocamentos e andanças, sempre narrados pelos moradores de Brejo dos Crioulos em nossas conversas, remetem-se ao que Santos (2014), amparada na abordagem proposta por Ingold (2000), chamou de "um conjunto de práticas e operações que revelam uma maneira singular de habitar o mundo, que é eminentemente móvel e multilocal" (SANTOS, 2014, p. 39). Perceber esse mundo em movimento, foi muito importante para a etnografia, me levando a tentar acompanhar o ritmo dos moradores. Caminhei por todas as localidades do território, frequentei os bares, reunióes, festejos e outros eventos. Visitei algumas roças e conheci algumas retomadas e ocupaçóes em andamento.

Os quintais, além de abrigarem as hortas, frutas e darem acesso às roças, também são espaços onde os moradores circulam livremente devido à proximidade das casas, cortando caminho pelos atalhos e trilhas, e indo em direçấo às mangas, que dividem estes espaços. Os animais também circulam nos quintais e dentro das casas. No interior destas, as visitas dos parentes e amigos fazem parte da rotina dos moradores, do mesmo modo que a parada para uma prosa e um café, geralmente acompanhado de biscoitos de goma doce ou salgados. As crianças circulam entre as casas e os quintais, brincam nestes espaços e seguem as trilhas entre as roças e os brejos para irem à escola e às lagoas.

É certo que, com início da luta, houve mudanças na paisagem, resultando em transformaçóes nas configuraçóes territoriais, já que, com as ocupações, os quilombolas começaram a retomar seus territórios. Nesse sentido, algumas mangas das fazendas acabaram se tornando hortas e roças, divididas entre as famílias que plantam coletivamente em uma mesma área, fazendo com que suas hortas e roças acabem sendo uma extensão da própria casa, onde o morador tem um cuidado especial e vai diariamente realizar o trabalho na terra. O capim que segura a terra, associado ao gado, componente da paisagem da monocultura nas mangas das fazendas, vai cedendo lugar às várias culturas: arroz, milho, feijāo, fava, abóbora, maxixe e melancia. Como disse Dona Isaldina, moradora de Brejo dos Crioulos, "a luta muda o mato, muda a paisagem".

Durante a realização do trabalho de campo, muitas eram as histórias e justificativas sobre as movimentações dos moradores de Brejo dos Criou- 
los, que não se restringem à comunidade e à região. Alguns narraram esses acontecimentos referindo-se aos casamentos, situaçóes de compra e venda das terras e por suas andanças pelo mundo lá de fora, como é o caso deste depoimento:

Eu mesmo, nessas minhas andanças, já fui para São Paulo, Belo Horizonte, Rio de Janeiro, para Recife, Salvador, Aracajú, Cachoeira do São Félix, cê entendeu? Essas áreas aí tudo a gente viajou, conhecendo os lugares. Porque náo tinha lugar certo da gente trabalhar aqui na comunidade. Aí desde 2007 que eu entrei na luta. Que eu estava lá pra fora, para o mundo lá de fora. Aí em 2007 eu peguei e voltei pra minha terra. (Vetinho, morador de Brejo dos Crioulos, 2014, grifos meus)

Com a escassez de trabalho na comunidade, devido à privaçáo do acesso a terra, os quilombolas necessitam complementar a renda familiar, o que estimula as saidas para trabalhar. As idas e vindas acabam constituindo uma estratégia de trabalho temporário muito importante.

A maioria do pessoal aqui saía para trabalhar no café, Piumhi ou Triângulo Mineiro. Tinha vez que saíam cinco ou seis ônibus só daqui de Brejo. Nessa fase aí muita gente parou de ir, pois tem seu local de trabalho e pode se manter dentro da área. Tá saindo alguns ônibus, mas não é intensificado igual era antes. Eu mesmo já trabalhei no café em Piumhi, São Gonçalo do Sapucaí, Perdizes e Serra do Salitre. (Nilson, morador de Brejo dos Crioulos, 2014)

O destino da maioria dos moradores são as plantações de café localizadas na cidade de Piumhi, no sul do estado mineiro. Na maioria das vezes os moradores se deslocam para as fazendas de café nos períodos de descida das águas e acabam retornando para a Festa de Bom Jesus. As cidades de Patrocínio e Santo Antônio do Amparo também são locais escolhidos, porém em menor escala. $\mathrm{O}$ dinheiro adquirido no café também circula na comunidade, sendo empregado na reforma e construção das casas, na compra de motos, aparelhos celulares e também na compra do enxoval de casamento. Além das saídas para trabalhar, os moradores, sobretudo os mais jovens, geralmente mudam para cidades como Belo Horizonte, Sáo Paulo (tanto a capital quanto cidades da regiáo metropolitana e do interior) ou até mesmo os municípios da regiáo como Montes Claros, Janaúba, Varzelândia e São João da Ponte. A maioria sai em busca de emprego ou quer dar continuidade aos estudos. 
É notável que, com o início do processo de retomada do território, ocorreu uma diminuiçáo significativa no fluxo dos trabalhadores, no entanto, muitos moradores e moradoras ainda saem para trabalhar em outras regióes de Minas Gerais e outros estados em suas andanças. A ausência física do território não implica na perda dos vínculos com a comunidade. Devido ao grande número de ligaçóes feitas e recebidas diariamente pelos moradores, o telefone assume grande importância nas relaçôes sociais, seja para contatar os parentes que estáo morando ou trabalhando em outras cidades da regiáo ou nos grandes centros e nas capitais, nas conversas diárias e na circulação de notícias sobre acontecimentos na comunidade, seja para definir estratégias e mobilizaçôes relacionadas à luta, como marcar reuniōes com seus parceiros ou combinar as caminhadas, ou quando são avisados sobre eventuais visitas e da necessidade de possíveis deslocamentos.

Em Brejo dos Crioulos, como forma de suprir a ausência dos telefones públicos, que se encontram quebrados, e também do sinal das operadoras de celular, que é instável, na maioria das casas existem as antenas. Na solução encontrada, geralmente um telefone celular é ligado a um cabo que tem conexáo direta com a antena. Os telefones são deixados sobre algum móvel ou colocados em algum suporte improvisado - em muitas casas visitadas -é possível observar aqueles feitos com o material proveniente de garrafas PET - geralmente no interior da residência, podendo, dessa maneira, receber chamadas e fazer ligaçóes. O telefone celular funciona, na maioria das vezes, como um telefone fixo, já que seu funcionamento fica restrito ao espaço doméstico. Entretanto, existem alguns lugares estratégicos conhecidos pelos moradores onde é possível obter sinal e fazer ligaçôes. $\mathrm{O}$ uso desses aparelhos, assim como outras coisas materiais - documentos, ferramentas, foguetes - em conjunto com a mobilização de diversos saberes, incluindo saberes técnico-burocráticos, são importantes para o acionamento da rede de parceiros e estão intimamente relacionados com o "fazer político" e a luta pela efetivaçáo dos direitos territoriais dos quilombolas. Nessa perspectiva, de acordo com uma liderança que participou de várias retomadas, "Nós estávamos com os papéis tudo amontoados e nunca que andava né? Não saía das gavetas e entrava para as outras gavetas, só ficavam engavetados. E nós resolvemos partir para a luta”, ele continua,

para os papéis andarem, ter andamento, nós tínhamos que, nós falamos assim, a caixa preta para andar tinha que bater, tinha que empurrar. Para os papéis andarem a gente teve que partir para os conflitos. Para garantir as coisas, o direito nosso e para desengavetar os papéis, para sair de uma entidade e ir para outra lá em cima né? Por exemplo, estava em São João 
da Ponte e de lá ia para Montes Claros. De Montes Claros para Belo Horizonte, de Belo Horizonte para Brasília. Aí nós tivemos que entrar e partir para a luta. (Edinho, morador de Brejo dos Crioulos, 2014)

A narrativa acima permite compreender que, para os quilombolas, é através das retomadas que os papéis e os documentos circulam através das instituiçôes. ${ }^{6}$ À medida que eles avançam na retomada do seu território, os processos (administrativos, criminais, agrários) saem da instância municipal e seguem para as instâncias e instituições estaduais e federais, aumentando as conexóes dos quilombolas e o alcance de suas reivindicaçóes. As lideranças também percebem a circulação e visualizam o trajeto dos papéis para além do seu território.

Os documentos ficam em vários lugares, fica um no INCRA, outro na Fundação Palmares, mas eles só saem de um lugar para o outro quando tem as retomadas. Quem estava na hora do embate da polícia, dos pistoleiros e fazendeiros, era eu que estava acompanhando. Entáo eu fiquei seguindo o papel, acompanhando o papel. (Véio, morador de Brejo dos Crioulos, 2014, grifos meus)

Os discursos das lideranças evidenciam que estas percebem as conexões e o alcance das instituições que são mobilizadas assim como os "canais institucionais" (MORAWSKA VIANNA, 2014) percorridos. Os quilombolas fizeram várias outras retomadas desde o início do processo de regularização fundiária. ${ }^{7}$ Essas ações nos permitem refletir sobre o acionamento e funcionamento da rede de parceiros, já que um mesmo evento mobiliza estratégias em locais diferentes. Enquanto os quilombolas retomam as terras, os seus advogados também mobilizam documentos - processos jurídicos - na tentativa de derrubar a liminar, ou seja, o mandado de reintegraçáo de posse.

$\mathrm{O}$ contato entre ambos é muitas vezes feito pelo telefone celular, que também conecta outros atores, define estratégias e através do qual são feitas as denúncias que acabam circulando pela rede, materializando-se em outros documentos, como as notas da CPT (Comissáo Pastoral da Terra) que divulgam as açóes dos quilombolas e as violaçóes e ameaças sofridas por estes. A multiplicidade de formas de ação política, contribuí para percebermos que, durante a luta, a política é vivenciada e acionada em diferentes contextos, tanto dentro do território quanto fora dele - nas reunióes, caminhadas, retomadas, mobilização de documentos e da rede. É pensando as estratégias inventadas e acionadas pelos quilombolas que acabamos 
compreendendo seus estilos de criatividade e suas formas de luta. Nessa perspectiva, a rede deve ser encarada como uma forma de "fazer política", onde relações em potência são acionadas pelo entrelaçamento de pessoas, saberes e coisas. São nas práticas, açôes e nos encontros que o desenho da rede vai tomando formato, assim como sua dinâmica e as suas conexóes. ${ }^{8}$

\section{Tecendo conexões: diálogos etnográficos possíveis}

A apresentação dos dois contextos teve aqui o objetivo de demonstrar as aproximaçóes e distanciamentos entre Pinheiro e Brejo dos Crioulos, evidentes por meio do uso de categorias semelhantes ou iguais, com sentidos próximos e reflexóes afinadas. $\mathrm{O}$ fato de habitarem o sertão mineiro, que possui um histórico econômico e político não muito dissonante, também confere certas proximidades, que derivam de um quadro macrossocial. Essas regiōes foram politicamente construídas como fornecedoras de mão de obra, e as saidas para trabalhar são uma das maneiras de se deslocarem, dando vasão a experiências de circulação por várias partes do Brasil. Sabemos que essas saídas foram inicialmente motivadas por questôes econômicas, mas que somente a economia não as explica.

Nas duas comunidades aqui analisadas, essas saídas são também formas de ampliarem o conhecimento sobre outros lugares, de estabelecerem cálculos familiares, de interagirem com o mundo. ${ }^{9}$ Distintamente do imaginário histórico sobre os quilombolas, vistos durante séculos como negros fugitivos e isolados das áreas urbanas, nossos interlocutores estão em redes de contato muito amplas, que englobam parceiros, instituiçōes, familiares, amigos, conhecidos, pesquisadores de várias partes do país e do cenário internacional.

Em Pinheiro e em Brejo dos Crioulos, correr atrás, buscar recursos, acompanhar a associação ou seguir os papéis, fazer andanças, realizar intercâmbios, dentre outras expressóes, nos parecem ilustrativas do quanto os movimentos políticos não se constroem desvinculados de outras esferas sociais, mas se conectam com movimentos ordinários, essenciais para as lutas e demandas coletivas. As açôes e os corpos desses companheiros de luta são motivados pela necessidade de encaminhamentos, que se desenrolam por meio de caminhadas.

Percebemos que as decisóes tomadas em uma assembleia ou em uma reunião política são importantes para as lutas mais amplas, mas não eximem nossos interlocutores do cuidado necessário às relaçóes travadas cotidianamente, que trazem em si múltiplos movimentos. Assim, deixar de cumprimentar devidamente os vizinhos, de visitar os doentes, de cuidar dos animais que se soltam e aparecem em seu terreno, de prevenir possíveis problemas 
entre cercas, de observar as idas e vindas entre as estradas, dentre outros, podem gerar cisōes graves nas relaçóes, suspender acordos informais que vigiam certa vicinalidade e impedir formas de circulaçáo e movimentação corriqueiras. Não se ater aos cuidados das relações e dos movimentos internos, sejam esses movimentos humanos ou não humanos, pode interferir de maneira ativa na qualidade de vida dessas comunidades, algo parecido com o que foi abordado por Comerford (2014), o qual procura, em meio "aos modos de movimentação", traçar possibilidades analíticas que

permitam levar em conta a importância dada, nesses universos sociais, não só do fato de que a movimentações em diferentes escalas, mas à forma das movimentaçóes em casas, às maneiras de convidar, chegar, permanecer, sair, voltar, evitar, frequentar, se deslocar enquanto performance por assim dizer. (COMERFORD, 2014, p. 110)

Entendemos, a partir do que é colocado pelo autor, que toda essa performance dá o tom de maneiras compartilhadas de se viver, fragmentadas em relaçôes familiares, de vizinhança, econômicas, políticas ou domésticas. Semelhante ao que Marcelin (1996) encontrou no Recôncavo Baiano, percebemos que as formas de circulação entre as casas dizem mais do que apenas sobre idas e vindas, mas também das formas como relaçóes vão sendo preservadas, afastadas, adensadas, de como as pessoas se formam e se constroem em sintonia com muitas casas e náo apenas um único lugar de moradia. Tanto em Pinheiro quanto em Brejo dos Crioulos, essas maneiras rotineiras não deixam de se constituírem como formas políticas, que se apresentam também na composição das associações, nas suas diretorias, na forma como desenham institucionalmente acordos com parceiros e com as redes que constroem.

Andar é bom para ganhar sabedoria náo apenas de seu terreno ou dos terrenos vizinhos e outros territórios, mas do movimento quilombola, da luta dos companheiros, da política nacional, de outros lugares, de outras situaçôes jurídico-burocráticas. A luta exige movimento, andanças, intercâmbios, participação em reunióes e audiências, deslocamentos e caminhadas, idas e vindas nas relaçóes ao longo dos anos. Dizemos que esses movimentos sáo múltiplos porque estáo longe de ser apenas territoriais, mas se aproximam do que Biondi observou em outro contexto, mas também observado em nossos campos de pesquisa: "Para que os movimentos possam prosseguir, outras pessoas são mobilizadas, assim como são acionados outros instrumentos como aparelhos celulares e cartas. Todos passam assim a compor o movimento" (BIONDI, 2014, p. 68, grifos da autora). 
Nesse universo de intensa mobilidade, tanto em Pinheiro quanto em Brejo dos Crioulos, os aparelhos celulares com as antenas de extensão de sinal telefônico são grandes aliados na manutenção de laços, seja entre familiares que estão para fora, seja na transmissão de notícias, pedidos, cobranças, parcerias, no contato com líderes de outras regióes, ONG's, sindicatos, pesquisadores e políticos. A inserção desse meio de comunicação propiciou melhorias significativas nas vidas dessas pessoas, assim como em suas lutas. Aliados aos telefones, que muitas vezes também são utilizados em altos de morros e também na cidade, outros meios de comunicação também auxiliam na divulgação de eventos das associações, cursos e demais atividades, como o rádio. Apesar de não ser mais a única ferramenta de transmissão de recados, os rádios são ouvidos em todas as casas pelas manhãs e, quando trazem um anúncio das atividades da associaçáo, propiciam um intenso falatório, de casa em casa e entre comunidades vizinhas.

Sabemos que todo experimento etnográfico é plausível de apropriaçóes, que podem não corresponder a uma escala esperada ou não apresentar conexóes e atingir o cerne das questóes levantadas. Porém, nos parece que nossas etnografias se afinam ao colocarmos em paralelo elementos que se deslocam de um dado lugar geográfico e se conectam a uma forma de açáo mais ampla, diante de um universo político de reivindicação. Pinheiro e Brejo dos Crioulos se aproximam por eles mesmos, suas lideranças se conhecem, trocam experiências, rezam uns para os outros. Aqui, o movimento aproxima realidades e se configura como um objeto de reflexão, além de uma prática multifacetada.

Os quilombolas mineiros sabem que, no universo dos papéis e das burocracias, o que manda é a açáo de seus corpos, as relaçóes constantes com parceiros, com técnicos, a busca incessante por serem visibilizados. Tudo isso se aprende na caminhada, como um dos princípios básicos para contarem num jogo político, seja local, regional, nacional ou internacional. Contudo, há de se levar em consideração que Pinheiro possui um adensamento institucional ainda diminuto em relação a Brejo dos Crioulos, que se envolveu em uma teia de agentes, instituiçóes e parceiros de maneira mais pungente devido seus duradouros conflitos territoriais.

Porém, em ambos, ir a muitas cidades, a muitos estados e até aos outros países é fundamental para uma comunidade se firmar, deixar de engatinhar, ganhar espaço, fazer os papéis andarem e resolver os conflitos. Diante de tanto movimento e mobilidade, nossas pesquisas lidam com o sentimento constante de que nunca estão atualizadas, não podem corresponder a uma estabilidade dos interlocutores ou de uma situação política. Como todo trabalho etnográfico, estamos limitados a um tempo de circunscrição da análise, mas não a um único espaço. $\mathrm{O}$ movimento é vivido de tal maneira 
que não podemos falar de um lugar delimitado geograficamente, por mais que estes territórios quilombolas tenham um sentido simbólico, relacional e histórico de preponderância na vida dessas pessoas.

Essas pessoas se envolvem em idas e vindas constantes, mas reconhecem seus territórios como um lugar para onde retornam, ao qual pertencem. $\mathrm{E}$ é justamente para continuarem tecendo tramas nesses lugares que o movimento é o principal mecanismo político. O desafio antropológico que nos é colocado segue o sentido de trazer essas questóes para o texto, para a escrita e para as reflexóes da área, uma vez que nas andanças e nas caminhadas se constrói mais do que idas e vindas. Constrói-se um jeito de se posicionar na política e no mundo.

\section{Notas}

1. Agradecemos enfaticamente aos debatedores do "GT 1: Teoria Antropológica e Escrita Etnográfica”, Catarina Morawska Vianna, Jorge Villela e Karina Biondi pelos comentários, sugestóes e incentivo para as aproximaçóes entre os dados de nossas pesquisas e a confecção deste artigo.

2. As palavras em itálico são expressóes e categorias nativas, e as expressóes e palavras entre aspas duplas se referem a termos e conceitos mobilizados por outros autores. A categoria movimento aparece em itálico quando se referir aos múltiplos usos tomados nos cotidianos das duas realidades em questáo. Para efeito de diferenciação, quando a mesma palavra for utilizada por outros autores da antropologia, a grafia será com aspas duplas.

3. A terra no bolo é analisada - dentre outros autores - por Galizoni (2007). Para a autora, o território se torna um bem patrimonial, deixado e repassado pelos ascendentes aos descendentes, o que faz do "dono da terra, antes de tudo, um herdeiro e a terra é, principalmente, um patrimônio formado pela família" (GALIZONI, 2007, p. 16).

4. Brejo dos Crioulos é formado pelas localidades de Araruba, Orion (Cabaceiros), Ribeirão do Arapuim, Caxambu I, Caxambu II, Furado Seco, Furado Modesto, Serra D'água e Tanquinho. A comunidade teve seu reconhecimento como remanescente de quilombos em 2004 pela FCP.

5. Também podem ocorrer alguns deslocamentos internacionais, como por exemplo, a ida do presidente da Associação Quilombola de Brejo dos Crioulos, José Carlos de Oliveira Neto, Véio, até Washington nos Estados Unidos, em Outubro de 2013, quando o mesmo participou de uma audiência da Comissão Interamericana de Direitos Humanos.

6. Neste trabalho não iremos nos aprofundar na discussão a respeito dos documentos. No trabalho de Mourthé (2015), o autor faz uma reflexão sobre as relaçôes entre os documentos e as retomadas no âmbito da luta pelo território em Brejo dos Crioulos, descrevendo as teorizações nativas em conexão 
com trabalhos que têm se dedicado a pensar os efeitos destes artefatos na teoria antropológica e na descrição etnográfica.

7. De acordo com Rainha (2013, p.16) "em um período de oito anos (2004 a 2012) ocorreram mais de 15 açóes desse tipo e, em consequência, mais de quinze reintegrações de posse obtidas pelos fazendeiros contra as famílias quilombolas". Para uma descrição aprofundada da dinâmica dessas ações, ver Mourthé (2015).

8. Nesta descrição etnográfica, a rede é um conceito nativo e não se trata de um conceito analítico, o que não nos impede de traçar conexôes com autores que propóem discussóes relacionados ao tema. Nessa perspectiva, dentre as várias contribuiçóes da proposta teórica de Latour (2012), podemos destacar o princípio da heterogeneidade do que o autor denomina como "redes sociotécnicas", tecidas pelas associações e conexôes entre vários elementos: pessoas, coisas, artefatos. De forma análoga, Morawska Vianna (2014a, p. 32), ao descrever etnograficamente relaçóes institucionais, enfatiza como coisas materiais e pessoas "se permeiam para compor saberes, mundos, relações". A rede é composta pela multiplicidade de elementos pessoas, documentos, e-mails, telefone celular e as ferramentas, usadas nas retomadas - sendo que estes não são pensados como meros "intermediários" (LATOUR, 2012), tampouco apenas como meras "coisas físicas que circulam" (MORAWSKA VIANNA, 2014). O interesse aqui é refletir sobre os efeitos desses elementos, que acabam sendo ressignificados politicamente na luta quilombola e na mobilização da rede.

9. As temáticas sobre "migração" e sobre deslocamentos populacionais têm contribuído progressivamente com abordagens mais cuidadosas sobre as decisóes de se deslocar, sobre a relação entre estas e os arranjos familiares, dentre outros aspectos. Superando a crítica sobre as generalizaçóes acerca dos "migrantes", iniciada na década de 1970 por Palmeira e Almeida (1977), os estudos mais recentes têm se detido em movimentos cotidianos, conectados com formas de circulação entre lugares e entre pessoas. Como exemplos, podemos citar os trabalhos produzidos pelo Núcleo de Antropologia da Política (Nuap) do Museu Nacional, como Guedes (2011), Rumstain (2012) e Teixeira (2014).

\section{Referências bibliográficas}

ALVES, Yara de Cássia. A casa raiz e o voo de sua folhas: família, movimento e casa entre os moradores de Pinheiro - MG. São Paulo, 2016. Dissertação (Mestrado em Antropologia Social) - Universidade de São Paulo.

BIONDI. Karina. Etnografia no movimento: território, hierarquia e lei no PCC. São Carlos, 2014. Tese (Doutorado em Antropologia Social) - Universidade Federal de São Carlos. 
COMEFORD, John Cunha. Vigiar e narrar. Sobre formas de observação, narração e julgamento de movimentaçóes. Revista de Antropologia (USP. Impresso), v. 57, p. 107-142. 2014.

GALIZONI, Flávia Maria. A terra construida. Família, trabalho e ambiente no Alto Jequitinhonha, Minas Gerais. Fortaleza: Banco do Nordeste do Brasil, 2007.

GOLDMAN, Márcio. Como funciona a democracia: uma teoria etnográfica da política. Rio de Janeiro: 7 Letras, 2006.

. Políticas e subjetividades nos novos movimentos culturais. Ilha-Revista de Antropologia. Florianópolis, v. 9, n. 1 e 2, PPGAS/UFSC. 2007.GUEDES, André Dumans. $O$ trecho, as mães e os papéis. Movimentos e durações no norte de Goiás. Rio de Janeiro, 2011. Tese (Doutorado em Antropologia Social) - Museu Nacional-UFRJ.

INGOLD, Tim. The Perception of the Environment. Essays in livelihood, dwelling and skill. London: Routledge, 2000.

LATOUR, B. Reagregando o social: uma introdução à Teoria do Ator-Rede. Bauru/Salvador: EDUSC/EDUFBA, 2012.

MARCELIN, Louis H. L'l-invention de la famille afro-americaine: famille, parenté et domesticité parmi ler noirs du Recôncavo da Bahia, Brésil. Rio de Janeiro, 1996. Tese (Doutorado) - Universidade Federal do Rio de Janeiro/ Museu Nacional.

MELLO, Marcelo Moura. Caminhos criativos da história: territórios da memória em uma comunidade negra rural. Campinas, 2008. Dissertação (Mestrado em Antropologia Social) - Universidade Estadual de Campinas.

MORAWSKA VIANNA, Anna Catarina. Os enleios da tarrafa: etnografia de uma relação transnacional entre ONGs. SãoCarlos: EdUFScar, 2014. 230 p.

MOURTHÉ, Pedro Henrique. Entre os documentos e as retomadas: movimentos da luta pelo território em Brejo dos Crioulos (MG). São Carlos, 2015. Dissertação (Mestrado em Antropologia Social) - Universidade Federal de São Carlos.

PALMEIRA, Moacir; ALMEIDA, Alfredo Wagner Berno de. A invenção da migração. Projeto emprego e mudança socioeconômica no nordeste. Rio de Janeiro: Museu Nacional, 1977.

RAINHA. Roberto. Quilombolas de Brejo dos Crioulos (MG): a árdua luta pela titulação do território étnico. In: STEFANO, D.; MENDONÇA, M. L. (Org.). Direitos humanos no Brasil 2013: Relatório da Rede Social de Justiça e Direitos Humanos. São Paulo, 2013.

RUMSTAIN, Ariana. Peóes no trecho: trajetórias e estratégias de mobilidade no Mato Grosso. Rio de Janeiro: E-papers, 2012.

SANTOS, Alessandra Regina. Nesse solo que vós estais, lembrai-vos que é de morrer. 
Uma etnografia das práticas de caminhar, conhecer e mapear entre os habitantes de Pedro Cubas, um remanescente de quilombo do Vale do Ribeira. São Carlos, 2014. Dissertaçáo (Mestrado em Antropologia Social) - Universidade Federal de São Carlos.

STRATHERN, Marilyn. Partes e todos: refigurando relaçóes. In: O efeito etnográfico e outros ensaios. São Paulo: Editora Cosac Naify, 2014.

TEIXEIRA, Jorge Luan. Na terra dos outros: mobilidade, trabalho e parentesco entre os moradores do sertão de Inhamuns (CE). Rio de Janeiro, 2014. Dissertaçáo (Mestrado em Antropologia Social) - Museu Nacional - UFRJ.

VIEIRA, Suzane de Alencar. Resistência e pirraça na Malhada: cosmopolíticas quilombolas

no Alto Sertão de Caetité, Bahia. Rio de Janeiro, 2015. Tese (Doutorado em Antropologia Social) - UFRJ/Museu Nacional.

WAGNER, Roy. A invenção da cultura. Trad. Marcela Coelho de Souza e Alexandre Morales. São Paulo: Cosac Naify, 2010.

autores Pedro Henrique Mourthé

É mestrando do Programa de Pós Graduação em Antropologia Social da Universidade Federal de São Carlos - PPGAS/UFSCAR. Possui graduação em Ciências Sociais pela Universidade Estadual de Montes Claros (2011). É pesquisador associado do LE-E (Laboratório de Experimentaçôes Etnográficas) da UFSCAR e do Grupo de Estudos e Pesquisa em Cultura, Processos Sociais, Sertáo, da UNIMONTES. Desde 2010 tem desenvolvido pesquisas em comunidades quilombolas do Sertão Norte Mineiro. Tem experiência nas áreas de Antropologia das Populações Afro-Brasileiras, Antropologia Rural e Antropologia Política.

\section{Yara de Cássia Alves}

É graduada em Ciências Sociais pela Pontifícia Universidade Católica de Minas Gerais (2008-2012). Mestranda do Programa de Pós Graduação em Antropologia Social da Universidade de São Paulo. (2013-atual) Membra do Hybris- Grupo de Pesquisa e Estudos sobre relaçôes de Poder, Conflitos, Socialidades. Pesquisa família e mobilidade de habitantes do Alto JequitinhonhaMG. Atua na linhas de pesquisa de Antropologia Política e Antropologia Rural. 